\title{
Integrating Communication into Senior Engineering Design Courses at the University of Manitoba
}

\author{
Anne Parker \\ Design Engineering \\ University of Manitoba \\ Winnipeg, Manitoba R3T 5V6 \\ aparker@cc.umanitoba.ca
}

\author{
Gary Wang \\ Mechatronic Systems Engg \\ Simon Fraser University \\ Surrey, BC V3T OA3 \\ garywang@sfu.ca
}

\author{
Kim Hewlett \\ Design Engineering \\ University of Manitoba \\ Winnipeg, Manitoba R3T 5 V6 \\ khewlett@mts.net
}

\begin{abstract}
:
In this paper, we will describe how we integrated communication into two capstone design courses in the Faculty of Engineering at the University of Manitoba. We will first look briefly at how the stand-alone technical communication course (offered early in the curriculum) serves as a cornerstone because it introduces students to the various genres of engineering communication and emphasizes the importance of communication within the practice of engineering. Integrating communication into courses like the Mechanical and Manufacturing Engineering design course (MECH 4860) and the Electrical and Computer Engineering design course (ENG 4600) means that technical and communications specialists work together toward helping senior engineering design students achieve their goal: designing a solution to an industry-based problem and then presenting their design in written, graphical and oral form. To do so, communications specialists become partners in the delivery of the course and in the assessment process. At the same time, the technical specialists can focus on assessing the design itself. Together, we can then evaluate a design according to what engineers must do on the job: solve problems and communicate solutions. The rubrics used to assess written communications are also intended as ways to help students see how each design element (like "project specifications") is important to the "deliverable," the report to the client. Finally, we will conclude with some observations about this past year and indicate what we would like to do next year.
\end{abstract}

\section{Introduction:}

At first glance, integrating communication into an Engineering course or into the entire Engineering curriculum can be a daunting task but, as Ford and Riley show [1], this integration has proven to be quite successful in various Engineering schools both here and in the U.S. Table I summarizes some of the features others have noted and shows how MECH 4860 compares.

Table I: Some Requisite Features for Integrating Communication

\begin{tabular}{|c|c|}
\hline \multicolumn{1}{|c|}{ Features } & \multicolumn{1}{|c|}{ MECH 4860 } \\
\hline $\begin{array}{c}\text { Shared [2] } \\
\bullet \quad \text { Teaching } \\
\bullet \quad \text { Course Design }\end{array}$ & $\begin{array}{c}\text { Shared } \\
\text { Stand-alone pre- } \\
\text { requisite (ENG } \\
2010]\end{array}$ \\
\hline $\begin{array}{l}\text { Communication } \\
\text { elements included in } \\
\text { instruction \& } \\
\text { evaluation [1] [2] } \\
\text { significant value } \\
\text { perceived } \\
\text { importance } \\
\text { all assignments }\end{array}$ & $\begin{array}{l}\text { Communication } \\
\text { elements included } \\
\text { in instruction and } \\
\text { capstone evaluation } \\
\bullet 60 / 40 \text { split } \& \\
\text { perceived }\end{array}$ \\
\hline $\begin{array}{l}\text { Synergy between } \\
\text { design \& } \\
\text { communication [2] }\end{array}$ & $\begin{array}{l}\text { importance } \\
\text { all }\end{array}$ \\
\hline $\begin{array}{l}\text { Coaching [3] } \\
\text { assignments }\end{array}$ \\
\hline
\end{tabular}

Yet, as successful as some of these other approaches are, the Faculty of Engineering at the University of Manitoba has itself developed a unique approach that we believe will prove to be successful as well. Unlike other approaches to introducing communication into engineering courses (such as writing-across-thecurriculum, or WAC), the approach adopted by the Engineering school at the University of Manitoba is one that includes stand-alone courses in communication and design early in the program, and then design courses later on. Recently, we also integrated communication into two of these senior design courses: the 
Mechanical and Manufacturing Engineering capstone course (MECH 4860) and the Electrical and Computer Engineering capstone course (ECE 4600).

Although communication had previously been included as at least one component in other, older versions of these courses, usually it was only as an ancillary. Now, however, as evidenced by the current versions of MECH 4860 and ECE 4600, integrating communication into the Engineering curriculum can lead to useful benefits for the students. For example, while the MECH 4860 course became a benchmark of how to mesh design and communication in the course's delivery and evaluation, the ECE 4600 course exemplified how intensive "coaching sessions" can be used as an important scaffolding tool to help students (as well as all the other stakeholders in the course, such as industry partners) realize the benefits of teaming and of revising.

\section{The Cornerstone: The Technical Communication Course (ENG 2010)}

The technical communication course is a second-year, stand-alone course that students complete before the capstone courses. There are many reasons why this approach has proven to be successful over the years. Unlike a course where technical communication is taught as part of an existing technical course, as is the case in the WAC approach, students in a stand-alone course have ample opportunity to learn more fully about the writing process as well as the team process [2, pp. 106-107]. But perhaps the most important reason, given what we have learned in the capstone courses, is that the technical communication course is a cornerstone upon which these other courses can build. Thus, integrating communication into a capstone course is more straightforward than it might have been had no such stand-alone course existed.

For example, based on a problemsolving model developed some years ago [4] [5], the course emphasizes what others, like Ford and Riley, also recognize; namely, that "the areas of technical communication and engineering necessarily converge" [1, p. 325]. As Shwom and Hirsch also state: "in many ways, engineering design and communication make ideal partners" [2, p. 105]. This partnership results partly because engineers solve problems, but also because they communicate solutions [2, p.107] [6, p. 13b5-1]. Moreover, engineers oftentimes can use the "same tools and techniques" for both engineering and communication design [2, p. 105]. The technical communication course demonstrates this synergy between communication and engineering design by detailing the basic problem-solving steps of information gathering and analysis; interpreting the information and conceptualizing a design solution; and, finally, decision-making so that the outcome, a final product, meets the needs of a client or user.

As well, the course introduces engineering students to the genres of engineering communication and helps them to shape their communications according to sound rhetorical principles of audience and purpose. Also helping them transition from the academy to the workplace is the course's emphasis on oral communication, teaming skills and project management skills. Another way to help students develop the "soft skills" that industry values is introducing information literacy into the course. As Tenopir and King have shown, acquiring information literacy affords students the means by which they can more easily access information both now and in their future professional lives [7].

Ultimately, it is this combination of problem solving, information literacy and rhetorical strategies that help to make the technical communication course a cornerstone in the engineering curriculum.

\section{The Capstone Courses:}

Because students have already taken this technical communication course as well as an introductory course in design, they have some background in both design and communication. Without this background, they would be hardpressed to complete the industry-based capstone projects in which an actual engineering problem must be solved. This is "real" engineering with actual clients, so the demands on the student teams are also real. Teams must consult with their clients (their target audience), and master the engineering details of this workplace situation. Then the student teams must prepare various documents and other communications for the client and for the course - all this within the short time available for teams to actually do all the tasks and solve the problem. This is an intensive, short-term project that demands project management skills, teamwork skills and communication skills. Thus, the course must be 
organized in a way that allows enough time for student teams to complete the project. Although most of the senior capstone courses only run for one term (the usual duration for a 3-credit hour course at the University of Manitoba), they typically have more classes and labs included. Consequently, the capstone courses have a higher "credit hour" value; for example, $\mathrm{MECH}$ 4860 is a 5 -credit hour course while ECE 4600 is a 6-credit hour course.

To give students the broadest academic and industry perspective possible, the capstone courses are also team-taught; that is, one engineering professor (the course instructor or coordinator) organizes the course and makes the arrangements for the design projects, for the industry and academic advisors, and for the various consultants. Along with the help of a teaching assistant, who handles most of the course administration, several co-instructors help the coordinator with all course-related activities. Now, part of the team includes the head librarian in Engineering, who assists students in finding information on standards and patents, as well as the communications specialists, who consult with students and assess the various written and oral assignments. Instead of a prescriptive approach to communication, however, one where rules and rigid protocols govern the writing process, the communication specialists strive for a more interactive environment, one where their function becomes more like that of a coach who helps students to shape their written and oral work. In this way, too, students can more fully experience all four modes of communication: written, oral, graphical and interpersonal communication [2, p. 107].

Above all, the delivery of the course and the assessment of the students are collaborative. As Shwom and Hirsch explain, both the engineering and the communications specialists need to "work to develop a shared agenda," including the design, teaching and evaluation of the course [2, [p. 105]. Everyone on the team must be an equal partner because design and communication are "ideal partners" [2, p. 105]. Design itself is a "communicationintensive activity," so a focus on communication enhances the quality of a design. In much the same way, a focus on design enhances the communication since reports and presentations must be "rhetorically and graphically designed to accomplish specific purposes for specific audiences" [2, p. 105].

Figure 1 illustrates the structure of the teaching team.

\section{Figure 1: Structure of the Capstone Teaching Team}

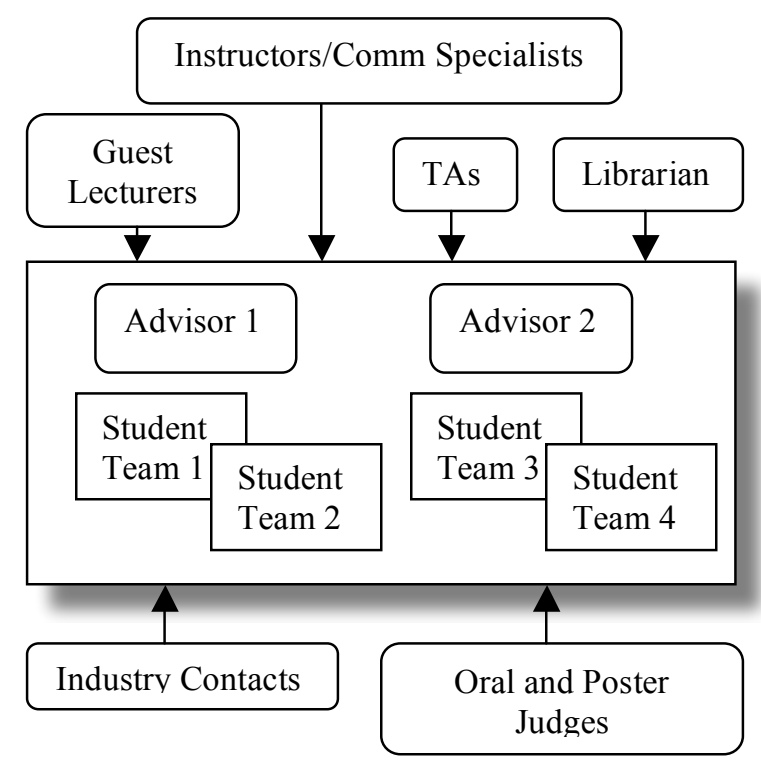

Ultimately, the goal of integrating communication into the capstone design courses was to build on what students had learned in their earlier courses, including technical communication, and to do so in a way that would enable the teams of engineering and communication instructors to focus less on introducing students to the principles of design and communication and more on creating their design - thereby fulfilling the CEAB requirement that students apply what they have learned in earlier courses and produce a useful design for their industry clients.

\section{The Mechanical and Manufacturing Engineering Capstone Course (MECH 4860): A 3-Phase Approach}

The senior capstone course in Mechanical and Manufacturing Engineering had its origin in a much earlier senior course developed by another professor. One of its distinguishing features was an emphasis on industry-based team projects with an ancillary focus on communication. A team of engineering faculty, invited speakers and industry consultants delivered the course material and assessed the students' written and oral work, both for the quality of the design and for the effectiveness of the communication. 
In the spring of 2007, the course coordinator and the technical communication coordinator began to talk about how communication could be more integral to the current design course, MECH 4860. And thus began a collaboration that successfully integrated communication into the teaching and assessment of engineering students and their design projects. Our course objectives were:

- to facilitate the transition from the academic world to the real world of the professional engineer;

- to give students the chance to experience open-ended problems, like those they will encounter in industry;

- to encourage design from a technical perspective as well as a social and environmental one; and

- to build on teamwork skills and on effective communication skills.

To ensure that our objectives are met, the course includes three lectures a week, where the coordinator, industry consultants and engineering faculty give lectures on practical design methods and the tools needed for both project management (such as a task matrix) and team management (such as leadership). As well, there are two labs, each an hour and a half long. One of these labs is for the teams to use as they wish; they may want to consult with the client or their advisor during this time. The other lab, held in a large room with several round tables, enables the capstone team and the students to interact. During this time, for example, students are able to chat informally with both the engineering faculty and the communication specialists. Additionally, the combined expertise of the capstone teaching team ensures that students are able to shape their oral and written work more effectively.

The course follows a three-phase design approach. Phase 1, project definition, comprises information gathering and analysis; here, student teams meet with representatives from the company sponsoring the project, discuss the problem the client wants solved, and begin to consider solutions. Phase 2, conceptual design, begins the process of interpreting the information collected by the team and shaping it into one or multiple design concepts that would address the problem outlined earlier. Phase 3 , the detailed design, involves developing the "best" concept as a complete design solution to the problem and then presenting the design to the client and to the team of capstone instructors (as most courses require) [3]. In each of these three phases, student teams prepare written and oral reports that describe their proposed design. Not only does this approach mirror the problem-solving approach outlined earlier, but also it reflects the writing process itself: gathering information and drafting a response; analyzing the information and reviewing the drafts to check for clarity and completeness; and preparing the final report, complete with graphics, and delivering it to the client.

To help the teams apply their engineering knowledge to an open-ended problem and complete all these phases successfully, the capstone course familiarized students with the steps and associated tools in the engineering design process. For example, students needed to recall what they had learned about project and team management in the technical communication course, and about the need for maintaining detailed records of the project and the team, such as logbooks and meeting minutes, The entire capstone team prepared material on these topics and later assessed how well the student teams integrated design as well as communication principles into their work.

To help the capstone team complete their assessments, the communications specialist devised a series of rubrics to assess all the required elements in the three major reports: the project definition report, the conceptual design report and the final report, each of which reflected one of the phases of the engineering communication and design process. Based on a 2-1-0 scale, the rubrics were designed to let students know whether each element was strong (2), competent (1), or weak (0). The rubric had three columns: the element to be assessed; the assessment based on the 2-1-0 scale; and, finally, the comments on each element. Each group of specialists considered the same fundamental areas when they read the reports, but the technical specialists focused primarily on the technical details while the communication specialists focused on rhetorical issues in more depth.

For example, the project definition report (assigned after student teams have read the client's definition of the problem) required students to define what they were proposing to do and determine how exactly they were going to proceed. In addition to a table of contents, the assignment called for students to have sections detailing the following:

- the problem background, where design teams situated both the problem and 
the project within the context of the overall company operation and defined the role of the project area within that context;

- the project objectives, where design teams explained the overall expectations of the team's design;

- the target specifications, where design teams analyzed customer needs and devised a list of corresponding technical specifications that provided quantifiable descriptors and their values;

- the constraints and limitations of size or cost or time;

- the project schedule, where the design team showed the work breakdown;

- approval by the client, where the client had to sign and date the report indicating their having read the proposal and approved what the design team intended to do.

The rubric mirrored these requirements in the first column; the second column showed how the section had been assessed according to the 2-1-0 scale, and the third column allowed space for comments.

Overall, this three-phase, integrated approach changed students' former perception that the "design is for the client, and the report is for the professor"; they soon came to realize that the design and the report are for both the professor and the client. Compared with previous years, the team of capstone instructors agreed that the students enrolled in the 2007 integrated course delivered better quality design solutions along with better design deliverables; that is, the communications they produced, such as posters and reports, were concomitantly of a higher quality than ever before. Even the overall course evaluation noticeably improved from a 3.2 (out of 5) in 2006 to a 3.6 in 2007.

Not only were the grades higher for the work the students produced, but also all of the clients indicated a willingness to adopt the design solutions that the student teams developed. One client who responded to questions about his levels of satisfaction with a project on stud welding and drilling was emphatic in his praise of the student team's level of commitment and hard work. He noted how well they worked together to produce what his company needed. He also stated that, if the trials were successful, the company would be implementing the design, perhaps one that looked different but nevertheless one that used the same concepts. He concluded by expressing the company's overall satisfaction with the students' professionalism and hard work, singling out the inclusion of all the drawings on a $\mathrm{CD}$ and the quality of the final report.

Thus, or the technical specialists, the integrated approach to the capstone course freed them to focus only on the design; trying to assess the communication of it no longer sidetracked them. For the communication specialists, the course became a model to be followed for the other capstone course to be briefly discussed here, the Electrical and Computer Engineering capstone course.

\section{The Electrical and Computer Engineering Capstone Course (ECE 4600):}

The ECE capstone course is unique in that it is a two-term course. Another unique feature is that the class does not always meet every week; students must therefore carefully organize when they will meet and how they will complete their work. Here, too, similar to the case in MECH 4680, the course coordinator of ECE 4600 prepares and delivers the lectures on topics such as proposals and oral presentations, but the entire teaching team (comprised of coinstructors and teaching assistants) contributes as needed to the course material. They are also present and available for consultations after a class. As well, the previous and the current coordinator for the course have written a detailed guideline for the students to follow. This document outlines in some detail the requirements for the final report, the logbook, the proposal and so on.

From the perspective of the communications specialists, this course had many positive features, but there was also one major drawback (primarily the result of staffing issues, which were later resolved): the communications specialists were not part of the team of capstone instructors from the very beginning, when teams were being formed and the students' collaborative work was starting. Hence, the communications specialists were less familiar with the students and the course, less involved with the team and the course dynamic, less steeped in what Ramey and Hudgins call the "culture" of the course [6, p. 13b5-3]. As a result, rather than being perceived as active participants in the whole process, they were seen as "add-ons." 
Because of this disconnection, students tended to perceive the communication side of design as less important than the technical side. All the previous assignments leading up to the final report had been prepared in a relative communication vacuum, even though most had taken the technical communication class earlier in their programs. Unlike the MECH 4860 experience, then, the experience in the ECE course felt less collaborative; often, the communications specialists felt like markers only and not active participants.

All that changed, however, when the communications specialists indicated their willingness to meet with students and help them shape their final written reports. After a slow start, students started to book appointments, and the instructors found it increasingly difficult to meet the demand. They were forced to focus on particular sections of a team's report rather than on the entire document. Nor were they able to have one-on-one sessions with individual students in order to diagnose possible writing problems and suggest solutions unique to them. In the end, they simply ran out of time, since the reports had to be submitted.

In the final analysis, although they managed to see 11 of the 21 teams enrolled in the course, the communications specialists agreed that much more could have been done from the beginning, especially since students verbally indicated that they had received invaluable help during these intense "coaching" sessions with the communications specialists. The perception of their place in the course changed as a result, from an "add-on" to a valued participant.

\section{Observations and Conclusions:}

Integrating communication into the senior capstone courses offered at the University of Manitoba has proven to be an exciting challenge, primarily because there were lessons to be learned during the course and beyond. Here are some of those lessons:

- the communications specialists must be involved throughout the senior capstone course and not just at times when there is an assignment due; they must have a definable presence in the class from the beginning;

- they must be involved in the day-to-day operation of the course as equal partners;
- to be perceived as equal partners, the marks assigned for the communications component must be, if not equal to the technical component (such as 50/50 would be), then at least of sufficient weight to be important - and to be perceived as important by the students;

- either outside of class or during the class, regular meeting times should be set up so that the communications specialists can meet on a regular basis with each team;

- these sessions should not merely provide prescriptive lessons in "do this, but not that" or in editing a student's work; rather, in order for active and lifelong learning to occur, these sessions should be more akin to coaching sessions where the communications specialists can guide the students and provide help and encouragement;

- having a stand-alone communication course like the Technical Communication course (ENG 2010), one that precedes the capstone course, means that students are better prepared for the demands of an industry-based project and are more open to the kind of coaching the specialists can do at the senior level;

- finally, the Engineering librarian should be even more involved in the capstone courses so that the information literacy skills learned in ENG 2010 can be further developed and students can become more proficient in researching standards, patents and so on.

Indeed, we are planning to implement these lessons into the 2008-2009 capstone courses by creating a more interactive classroom and by encouraging more time for meetings between students and the communication specialists.

Therefore, we would argue that a senior capstone course that integrates communication into the overall engineering design process can be most successful if stand-alone courses in both communication and design precede it. Additionally, both communication and design in the capstone course must be meshed emphasized in the course delivery and assessed throughout the evaluation process. In this way, both communication and design are emphasized as important components in an engineering student's education. 


\section{References:}

[1] J.D. Ford and L.A. Riley, "Integrating Communication and Engineering Education: A Look at Curricula, Courses, and Support Systems," Journal of Engineering Education, October 2003, pp. 325-328.

[2] B. Shwom and P. Hirsch, "Re-envisioning the Writing Requirement: An Interdisciplinary Approach," Business Communication Quarterly, v.62, no.1, 1999, pp. 104-107.

[3] J. Emanuel and D. Kerns, "Industry-Based Capstone Design Projects: You Can't Sell the Solution If You Can't Communicate," ASEE Annual Conference Proceedings, 2007, Session AC 2007-2246, 12 pp.

[4] A. Parker, "A Case Study Workshop and a Problem-Solving Approach to Technical Communication," Technostyle, v.8, nos.1-2, 1989, pp. 38-51.

[5] A. Parker, "Problem Solving Applied to Technical Writing," The Technical Writing Teacher, v.17, no.2, 1990, pp. 95-103.

[6] D. Ramey and J. Hudgins, "The Evolution of Integrating Writing into Engineering: Tracing Iterations of Writing Instruction in a Sophomore Engineering Course," in Proceedings, Frontiers in Education Conference, v.3, 1999, pp. 13b5-113b5-5.

[7] C. Tenopir and. D.W. King, Communication Patterns of Engineers, Piscataway, NJ, IEEE Press, 2004. 